\title{
A Divisão de Tarefas Domésticas entre Homens e Mulheres no Cotidiano do Casamento $^{1}$
}

\author{
The Division of Household Labor Between \\ Men and Women in Everyday Marriage Life
}

La División de Tareas Domésticas entre Hombres y Mujeres en el Cotidiano del Casamiento

Bernardo Jablonski

Pontifícia Universidade Católica do Rio de Janeiro

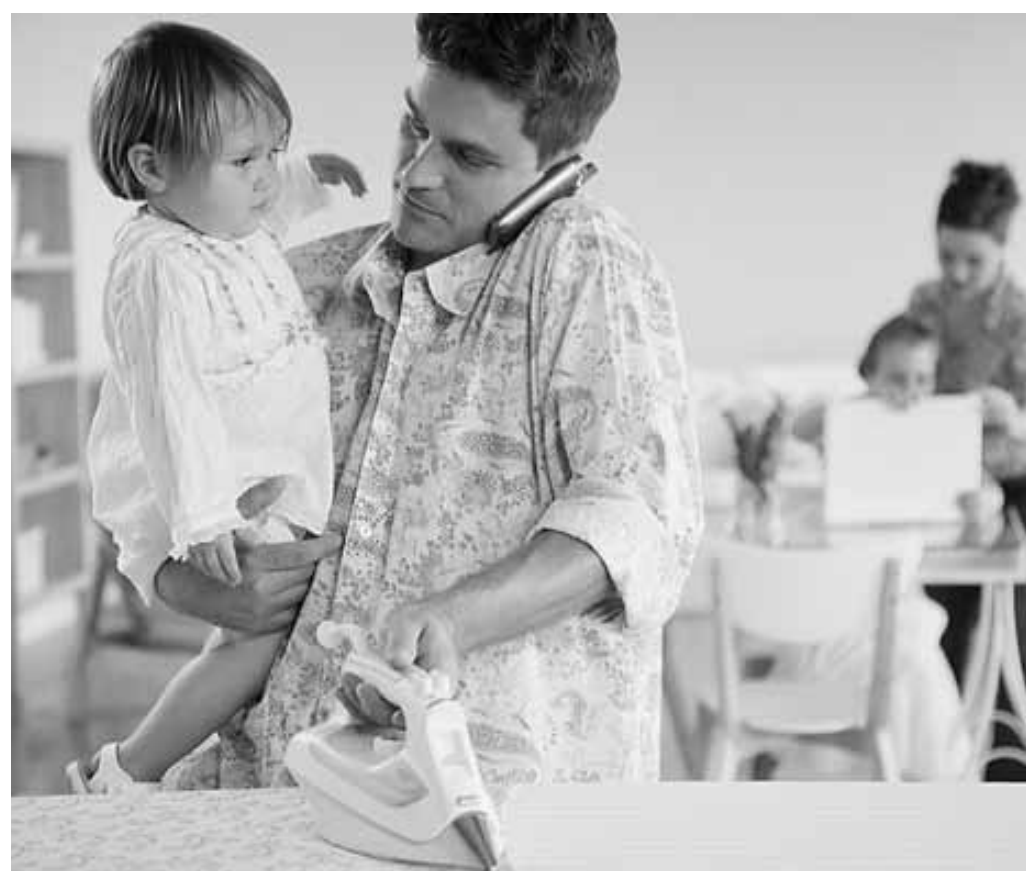


Resumo: O presente trabalho visa a investigar como se dá a negociação de tarefas dentro do lar face às novas demandas impostas a reboque do movimento de emancipação feminina e do ingresso maciço das mulheres no mercado de trabalho. Procuramos avaliar atitudes e comportamentos acerca de diversos tópicos relativos ao cotidiano da vida em comum entrevistando 20 membros de casais heterossexuais de classe média, com idades entre 30 e 40 anos, com pelo menos 5 anos de união e ao menos um filho. Entre os principais resultados, destacamos que, apesar da existência de uma dupla jornada de trabalho e das dificuldades demonstradas pelos homens em compartilhar de forma igualitária as tarefas domésticas recaindo sobre a mulher o peso maior (cuidar da casa e das crianças, fazer compras, arrumar, lavar e passar, etc.) - não observamos, como seria esperado, um aumento considerável de conflitos na relação marital.

Palavras-chave: Gênero. Atitudes. Tarefas domésticas. Casamento.

\begin{abstract}
The current article investigates how housework negotiations occur inside the home, due to the new demands that emerged with the women's lib movement and the increase of women in labor-force participation. We evaluated attitudes and behaviors regarding several topics in a couple's life by interviewing 20 heterosexual middle-class couples, with ages between 30-40 years, with at least 5 years of marriage and at least 1 child. Among our major results, we highlight the fact that despite the existence of a double working schedule and the difficulties expressed by men in sharing household chores in an egalitarian fashion - which greatest weight relies upon women (caring for the house and the children, shopping, organizing, doing laundry, ironing, etc.) - we did not observe, as could be expected, a great increase in conflicts in marital relationship.
\end{abstract}

Keywords: Gender. Attitudes. Housework. Marriage.

Resumen: El presente trabajo visa a investigar cómo se da la negociación de tareas dentro del hogar frente a las nuevas demandas impuestas a remolque del movimiento de emancipación femenina y del ingreso macizo de las mujeres en el mercado de trabajo. Procuramos evaluar actitudes y comportamientos acerca de diversos tópicos relativos al cotidiano de la vida en común entrevistando a 20 miembros de parejas heterosexuales de clase media, con edades entre 30 y 40 años, con por lo menos 5 años de unión y al menos un hijo. Entre los principales resultados, destacamos que, a pesar de la existencia de una doble jornada de trabajo y de las dificultades demostradas por los hombres en compartir de forma igualitaria las tareas domésticas - recayendo sobre la mujer el peso mayor (cuidar de la casa y de los niños, hacer compras, arreglar la casa, lavar y planchar, etc.) - no observamos, como sería esperado, un aumento considerable de conflictos en la relación marital.

Palabras clave: Género. Actitudes. Tareas domésticas. Casamiento.

A ideia de pesquisar nessa área proveio do fato de que a atual família nuclear urbana e a instituição do casamento passam por momentos de transição. Profundas mudanças de ordem socioeconômica e cultural vêm levando o casamento contemporâneo a um estado de instabilidade, como se infere do aumento do número de separações, a tal ponto que, aproximadamente, cinquenta por cento das uniões tendem à ruptura em alguns anos (Coontz, 2005; Demo, 2007; Epstein, 2002; Schoen \& Canudas-Romo, 2006). Embora esses números se refiram aos EUA, pesquisas realizadas nos grandes centros urbanos ocidentais indicam a mesma tendência, variando apenas a magnitude da taxa em questão. No Brasil, por exemplo, tomados os dados relativos entre os anos 1997 e 2007, o número de divórcios aumentou
$200 \%$, enquanto o de casamentos legalizados cresceu apenas pouco mais de 26\% (Instituto Brasileiro de Geografia e Estatística [IBGE], 2007). Além disso, evidências anedóticas relativas às populações de classes carentes, que residem nas cidades grandes ou em sua periferia, mostram igualmente que a crise do casamento não se atém apenas a determinado tipo de cultura/classe social (Jablonski, 1998).

Esses dados revelam, a nosso ver, mudanças significativas no âmbito da família e do casamento. De certa forma, a própria definição de família parece estar em questão, já que o modelo herdado dos anos 50, no qual o pai sai para trabalhar e a mulher fica em casa, dedicada ao lar e aos filhos, parece estar deixando de ser hegemônico. Na verdade, esse modelo, dividido em rígidas esferas e visto como tradicional, foi, historicamente, apenas 
uma primeira versão do que chamamos de família moderna (Skolnick, 2006). De fato, o período compreendido entre 1900 e meados da década de 70, ainda que de curta duração, produziu forte impacto sobre o imaginário popular. Embora o casamento tenha sempre sido uma parceria entre homens e mulheres, esse típico arranjo de uma era, no qual as mulheres se dedicavam às tarefas domésticas/ cuidado dos filhos enquanto os homens saíam de casa para se devotar ao trabalho e à carreira, deitou raízes profundas em termos de ideais de casamento e de papéis de gênero a serem desempenhados (Amato, Booth, Johnson, \& Rogers, 2007).

De qualquer modo, hoje em dia, nos grandes centros urbanos ocidentais, encontram-se em maior ou menor número famílias nas quais pai e mãe trabalham fora, compostas por pais e/ou mães em seus segundos casamentos, por mães solteiras que assumiram (por opção ou não) a maternidade e passaram à condição de famílias uniparentais, por casais sem filhos (por opção ou não), por casais que moram juntos e por casais homossexuais. Todas as formas alternativas se contrapõem ao modelo tradicional, e vão redefinindo na prática o conceito de família ou as expectativas quanto ao casamento tradicional. Ainda segundo o IBGE (2005), 50\% dos domicílios estão organizados em torno de formas nas quais, no mínimo, um dos pais está ausente.

\section{Entre propostas igualitárias e práticas tradicionais}

A par das diferenças culturais e dos avanços a reboque do movimento feminista, parece persistir uma visão conservadora dos papéis dos cônjuges no que se refere às tarefas domésticas e à responsabilidade pelo cuidado e educação dos filhos. Teoricamente, as perspectivas dos recursos econômicos relativos e de gênero têm predominado na base da literatura a respeito. A primeira enfatiza os aspectos racionais/econômicos e leva em conta os ganhos relativos de homens e mulheres na alocação de tarefas domésticas. Essa perspectiva pressupõe maior igualdade em função dos crescentes e substanciais ganhos femininos em termos de educação e salários, entre outros (Blood \& Wolfe, 1960; Brines, 1994; Coltrane, 2000).

Já a perspectiva de gênero aponta a dificuldade de mudanças substantivas face à profunda internalização de bem estabelecidas diferenças de atuação. Essa concepção, ancorada em vieses culturais solidamente enraizados em sociedades patriarcais, superaria a influência mais individual relacionada aos cônjuges ligada a educação, ganhos individuais, status e disponibilidades temporais -, fazendo com que predominasse a visão tradicional de divisão de tarefas (Thompson, 1995). Em outras palavras, a realidade macrossocial sobrepuja a microssocial no que diz respeito à assunção de tarefas dentro do lar, de acordo com o que prega uma visão teórica mais alinhada com a postura de perspectiva de gênero (Berk, 1985; Ferree, 1990) - que atrela a construção simbólica do feminino à realização da maior parte dos trabalhos domésticos. Nesse sentido, seria mais difícil para homens adotarem posturas mais femininas (realização de tarefas domésticas). Ambas as suposições encontram respaldo em pesquisas sobre o tema (Bianchi, Milkie, Sayer, \& Robinson, 2000; Sayer, Philip, \& Casper, 2004).

O foco do presente estudo está no cotidiano dos casais sob a ótica da divisão das tarefas domésticas e dos cuidados com os filhos face às consequências do movimento de emancipação feminina. Acreditamos, em consonância com a vasta literatura a respeito (Amato et al., 2007; Artis \& Pavalko, 2003; Baxter, Hewitt, \& Haynes, 2008; Coontz, 2005; Diniz, 1996; Féres-Carneiro, 1998; Goldenberg, 2000, Robinson \& Hunter, 2008; 
Rocha Coutinho, 2003, 2004, 2007; Thistle, 2006; Vaitsman, 1994), que esse movimento veio transformar profundamente as relações de gênero, aliado à entrada maciça da mulher de todas as classes sociais no mercado de trabalho e de suas consequências casamentos mais tardios, diminuição no número de filhos, maior independência por parte das mulheres e aumento de conflitos gerado pela busca da igualdade de direitos.

Assim, parecem cada vez menos frequentes os arranjos matrimoniais em que apenas um dos parceiros se encarrega sozinho do sustento da família. As mulheres se voltam, mais e mais, para o trabalho fora de casa, não só porque ele possibilita atingir melhor padrão de vida para a família mas também pelo fato de o sucesso profissional ser encarado como uma forma de realização pessoal e social (Goldenberg, 2000; Rocha-Coutinho, 2003; Thistle, 2006), além de assegurar maior independência financeira, algo importante em tempos nos quais o casamento nem sempre é duradouro. Em consequência, o número de horas despendido nas tarefas de casa diminuiu sensivelmente nos Estados Unidos, no Canadá e na Europa (Jacobs \& Gerson, 1998; Sayer, 2005), pari passu a um aumento da quantidade de horas dedicadas ao trabalho fora de casa por pessoas na faixa etária compreendida de 25 a 45 anos, normalmente, pais com filhos pequenos (Amato et al., 2007; Daly, 2003).

No Brasil, babás e empregadas domésticas fazem uma diferença, no sentido de suprir em parte a ausência das mães que se dedicam mais intensamente ao trabalho fora de casa, ainda que haja dúvidas acerca do número real de lares que incluem a presença de empregadas domésticas. Para o IBGE (2000), apenas $11 \%$ dos domicílios brasileiros contam com a presença de uma empregada doméstica, morando ou não na residência, o que nos leva, sem dúvida, a contextualizar os resultados das pesquisas e estudos feitos nas culturas onde não há esse tipo de mão de obra disponível, ao contrário do Brasil e de outros países da América Latina.

Araújo e Scaflon (2005), após ampla pesquisa realizada em 2003, que contou com 2000 domicílios em 24 Estados brasileiros, chegaram à mesma conclusão, ao constatar que a maior parte do trabalho doméstico entre nós ainda continua sendo majoritariamente uma atribuição feminina. Assim, para essas autoras, o ingresso das mulheres no mercado de trabalho não implicou uma divisão mais igualitária dos trabalhos domésticos, ainda que haja indícios de maior participação masculina no que diz respeito ao cuidado com os filhos (mas não nas tarefas domésticas).

Rocha-Coutinho (2003, 2004, 2005) observa igualmente em suas pesquisas que - a par de um discurso social igualitário - tanto homens como mulheres cariocas parecem endossar o ponto de vista (com diferentes níveis de consciência) de que a casa e os filhos são ainda responsabilidade maior da mulher, cabendo ao homem o provimento financeiro. Artis e Pavalko (2003) lembram que, em consonância com a perspectiva de troca social, ao aumento da taxa de mulheres na força de trabalho deveria corresponder uma queda em seus níveis de atividade dentro do lar, somada a uma divisão de trabalhos intralar mais equilibrada entre homens e mulheres. Mas as mudanças nesse sentido têm se mostrado muito pequenas e insatisfatórias, do ponto de vista feminino, em que pese a observação de que entre gerações mais jovens estaria havendo uma distribuição mais igualitária de afazeres e responsabilidades domésticas, a reboque de concepções de vida ideologicamente alinhadas com uma visão de papéis de gênero mais igualitária (perspectiva de gênero).

Por outro lado, na França, em 2000, segundo pesquisa levada a cabo pela CNSR (reportado 
no jornal Le Monde), $80 \%$ dos pais, apesar do discurso igualitário, na prática, não participam em quase nada no que diz respeito à educação e aos cuidados infantis e muito menos aos afazeres domésticos. A pesquisa em questão, após entrevistas com mil pais, confirma a noção de que, entre as bem intencionadas atitudes igualitárias e a prática do dia a dia, a distribuição de tarefas dentro de um lar ainda é bastante marcada pela divisão sexual, e as mulheres arcam com a maior parte delas.

Da mesma forma, para Coltrane (2000), embora a contribuição masculina nos afazeres dentro do lar esteja aumentando, as mulheres ainda trabalham pelo menos duas vezes mais que os homens cumprindo as tarefas rotineiras do lar: cuidar das crianças, lavar e passar roupas, fazer compras no supermercado, limpar a casa, etc. Para esse autor, as consequências dessa injusta divisão são vistas, frequentemente, em sentimentos de injustiça, sintomas de depressão e de insatisfação com o casamento por parte das mulheres. Por outro lado, maior participação masculina nessas tarefas seria um excelente preditor de satisfação marital. A percepção de que estaria havendo uma injusta divisão de tarefas levaria, pois, a um sensível aumento de conflitos e à diminuição da satisfação marital (Blair, 1988; Greenstein, 1996; Kluver, Heesink, \& Van de Vliert, 1996; Lavee \& Katz, 2002).

Fuwa (2004) lembra que, de fato, houve progressos na área, de vez que a participação feminina nas tarefas domésticas vem caindo substancialmente. Assim, por exemplo, entre os anos 60 e 90, o número de horas despendidas nesse tipo de tarefas teria caído pela metade para as mulheres e dobrado para os homens norte-americanos (Bianchi et al., 2000). Concomitantemente, no entanto, persiste a noção de segregação por gênero, já que caberia à mulher a responsabilidade por inúmeras tarefas domésticas tidas como essencialmente femininas.

Pleck (1997) confirma, em suas pesquisas, que a mulher tem convocado - ou ao menos tentado - cada vez mais seu companheiro a participar dos cuidados com os filhos. O autor encontrou fatores que podem ajudar o envolvimento do pai, como, por exemplo, a idade (filhos pequenos sensibilizam mais do que adolescentes), o sexo dos filhos (meninos também parecem receber mais atenção dos pais) e o dia da semana (fins de semana parecem o período mais apropriado para que o pai exerça a sua função).

Em nossos estudos anteriores, notamos igualmente (Brasileiro, Jablonski, \& FéresCarneiro, 2002; Jablonski, 1988, 1996, 2001, 2003), no que diz respeito às atitudes, um crescente interesse dos homens em participar, cada vez mais, dos cuidados com os filhos. Porém, ao passarmos para o campo dos comportamentos, ou seja, da ação propriamente dita, isso não se daria, como se houvesse uma promessa de mudança que não é cumprida, circunstância que tende a gerar frustração nas mulheres.

Na citada pesquisa de 2005, do IBGE, constatou-se igualmente que a crescente participação das mulheres no mercado de trabalho não tem reduzido substancialmente a sua jornada nos afazeres domésticos. Assim, o tempo dispensado nestes é de 9,1 horas semanais para os homens e de 21,8 para as mulheres. Para as mulheres casadas com filhos menores de 14 anos, os números chegam a 29 horas semanais.

Essa situação de disparidade de papéis seria vivenciada pelas mulheres, aparentemente, de forma dolorosa, uma vez que há uma promessa no ar de igualdade de funções, alimentada por atitudes dos próprios homens, o que ocasiona uma expressiva fonte 
Para Jacobs

(2004), um modelo mais igualitário, excelente na teoria, tem trazido na prática inúmeros problemas, em função de expectativas e responsabilidades ainda sob forte influência de papéis de gênero predeterminados. adicional de conflitos dentro de uma área já suficientemente carregada de problemas. Diante desse quadro, muitas mulheres sentirse-iam traídas e sobrecarregadas, visto que a divisão igualitária dos papéis, não se dando na prática, contribuiria para que a mulher se sentisse cada vez mais solitária em suas funções diárias (Jablonski, 1998). Por outro lado, no entanto, Araújo e Scalon (2005), em seu estudo citado por nós anteriormente, com pessoas predominantemente de baixa renda, reportaram baixos índices de conflito ocasionado pela discrepância entre o que homens fazem em casa e o que as mulheres esperam que eles façam. As autoras aventam a possibilidade da existência de tensões significativas latentes, ainda que as mesmas não se traduzam em conflitos explícitos entre homens e mulheres.

Demo (1992) corrobora a existência de mudanças ao verificar que a participação masculina tem se tornado mais efetiva, principalmente entre os pais com menos de 30 anos de idade ou com filhos em idade pré-escolar. Em conformidade com a maior parte dos estudos, o autor reconhece que as mudanças não têm sido as esperadas, embora a participação dos pais tenda a aumentar à medida que os filhos crescem, com adolescentes recebendo mais atenção do que bebês, uma vez que pais não amamentam e mães não costumam acompanhar os filhos em jogos de futebol. Bianchi et al. (2000) e Sayer, Bianchi e Robinson (2004) também engrossam as fileiras dos que reportam um aumento substancial de homens se engajando mais em tarefas domésticas e cuidados com as crianças, desde os anos 60.

Para Jacobs (2004), um modelo mais igualitário, excelente na teoria, tem trazido na prática inúmeros problemas, em função de expectativas e responsabilidades ainda sob forte influência de papéis de gênero predeterminados. Dessa forma, papéis mais tradicionais estariam sempre competindo com as escolhas mais contemporâneas, o que acarretaria uma confusão acerca de que paradigmas seguir. Isso estaria levando os casais à formulação de expectativas irrealizáveis bem como a sentimentos mútuos de incompreensão, de ressentimento e, finalmente, de rejeição.

Assim, o que um significativo conjunto de estudos tem demonstrado, em que pese algumas mudanças, é que inúmeros aspectos da vida cotidiana parecem continuar imputados à responsabilidade feminina. A presente pesquisa pretende debruçar-se justamente sobre esses aspectos da vida em comum, investigando como a alteração de papéis resultante da emancipação da mulher vem se refletindo na organização interna dos lares, averiguando até onde as mudanças de atitudes e ideias acerca do papel feminino se concretizam em uma efetiva divisão das tarefas domésticas (discurso x prática), se existe ou não a denominada tripla jornada de trabalho da mulher, incluídos os gastos em tempo e energia na esfera dos cuidados com a beleza) e ainda em que medida essa nova realidade vem acrescentando pontos de atrito à vida conjugal.

\section{Objetivos}

O presente trabalho teve como objetivo maior pesquisar o cotidiano do casamento de jovens casais que se dividem entre a vida familiar e a profissional. Procuramos investigar como vem se dando entre os membros de casais urbanos de classe média a negociação de tarefas dentro do lar face às novas demandas impostas pelo ingresso maciço das mulheres no mercado de trabalho.

Assim, face à dupla jornada de trabalho e às dificuldades demonstradas pelos homens em compartilhar de forma mais igualitária as tarefas ditas domésticas (cuidar da casa e das crianças, fazer compras, arrumar, lavar e passar, entre outras atividades), seria de 
se esperar um aumento considerável de conflitos dentro dos casamentos de hoje. A existência (e em que grau) de atritos e a forma como os cônjuges lidam com essas demandas antagônicas - fruto da herança de papéis de gênero tradicionais em conflito com as perspectivas contemporâneas mais igualitárias - foi o foco principal do presente estudo.

\section{Metodologia:}

\section{Sujeitos}

Vinte (20) membros de casais heterossexuais de classe média, com idades entre 30 e 45 anos (com pelo menos 5 anos de união), ambos trabalhando fora de casa, e com a condição de terem ao menos um filho.

\section{Instrumentos e procedimentos}

Lançamos mão de uma metodologia qualitativa, utilizando como instrumento entrevistas com roteiro semiestruturado ( $v$. anexo I). As entrevistas foram realizadas na residência dos casais, sendo cada um dos membros entrevistado separadamente em cômodos distintos e as entrevistas gravadas e transcritas na íntegra, com duração aproximada de 30 minutos por cônjuge. Cabe frisar que as informações prestadas não foram reveladas ao parceiro, tendo sido utilizados nomes fictícios por motivos éticos, sem vínculos de afetividade entre os entrevistados e entrevistadores para que estes não ficassem inibidos ao dar algum tipo de resposta, o que poderia afetar os resultados.

Seis grupos de temas foram abordados (informações gerais sobre o entrevistado, opinião sobre o casamento e a educação dos filhos, lazer, vida doméstica cotidiana, cuidado dos filhos e apreciação pessoal sobre a divisão das tarefas), procurando conferir a maior abrangência possível ao nosso estudo. Não foram feitas perguntas ligadas à intimidade do casal ou a qualquer outro tema que pudesse ser considerado embaraçoso.

\section{Análise dos dados}

Para a devida avaliação do material obtido através das entrevistas, procedemos a uma análise do conteúdo, como proposto por Bardin (1979), entre outros autores. Assim, as categorias de análise foram estabelecidas a partir dos dados logrados nas entrevistas, embora a própria seleção de temas (mencionados acima) tenha contribuído para a constituição das categorias.

\section{Resultados}

Com relação à nossa amostra, a média de idade das mulheres foi de 33,45 anos e a dos homens, de 38,22 anos. A duração média dos casamentos foi de 9 anos, e metade da amostra tem 2 filhos, e metade, 1 filho, sendo que 2 homens não têm filhos, mas exercem a função de padrastos.

Os entrevistados tinham profissões as mais variadas, sendo predominante o exercício do trabalho fora de casa, com jornada préfixada. No caso dos homens, contamos com engenheiros, administradores, economistas, comerciantes e consultores, dentre outras profissões. Entre as mulheres, predominaram advogadas, comerciantes e artistas. Os homens despendiam, segundo seus relatos - no trabalho fora de casa - em média 9,4 horas por dia, enquanto as mulheres 7,5 horas, dados consonantes com os de outras pesquisas (Amato et al., 2007; Sayer, 2005). Entre as questões introdutórias, opinando sobre o que faz durar um casamento, as mulheres valorizaram mais o respeito do que $\mathrm{o}$ amor, e os homens, o inverso. Esses resultados vão de encontro às crenças de que mulheres seriam mais românticas e idealizadoras que os homens, embora estudos conduzidos nas últimas décadas tenham mostrado o inverso, isto é, que os homens é que seriam mais 
românticos, apaixonando-se primeiro e subscrevendo, comparativamente, mais mitos e crenças a respeito ("amor verdadeiro é para sempre", "sabemos quando encontramos a pessoa certa", etc.). As mulheres, por sua vez, seriam mais pragmáticas, levando em consideração os recursos socioeconômicos de seus pretendentes e acreditando que relações românticas devem ter uma sólida base de amizade (Dion \& Dion, 1996; Fehr \& Broughton 2001; Hendrick \& Hendrick, 1995; Fehr, 2006). Outros autores, no entanto, consideram os resultados das pesquisas simplesmente não conclusivos (Moore, Kennedy, Furlonger, \& Evers, 1999; Peterson \& Shoemaker, 1993; Singelis, Choo, \& Hatfield, 1995), o que aponta a necessidade de se pesquisar mais a fundo as diferenças de gênero quanto às concepções do amor.

Em relação aos fatores que levam à manutenção do casamento, foi digna de nota - e igualmente de espanto - a quase ausência de referência à sexualidade. Ou os sujeitos partem da premissa que o sexo é obviamente parte integrante do casamento e que, por isso, nem precisa ser citado, ou esse não é um elemento importante para a manutenção do casamento, o que nos parece pouco provável. Pesquisa Datafolha de 2007 também chegou a resultados similares em uma amostra com mais de 2000 entrevistados, ainda que com uma pergunta um pouco diferente $(O$ que é mais importante em um casamento?). As respostas mais frequentes foram: fidelidade, $38 \%$; amor, $35 \%$; honestidade, $15 \%$, e filhos, $5 \%$. A vida sexual satisfatória foi valorizada por apenas $2 \%$ da amostra, o que deve, a nosso ver, nortear futuras pesquisas que procurem averiguar porque o sexo não é citado como fator importante para a manutenção do casamento.

Entre as vantagens de estar casado, obteve destaque, entre os homens, a menção à constituição de família, o que coincide com outros estudos, como os levados a cabo por Féres-Carneiro (1998, 2001) e Magalhães (1993), que observaram a importância conferida a essa questão pelos homens. Igualmente no que diz respeito à segurança, tanto financeira quanto emocional, os homens, preponderantemente, citaram esse fator como vantagem do casamento.

$\mathrm{Na}$ indagação acerca das desvantagens

do casamento, detectamos diferenças perceptivas entre homens e mulheres, com os primeiros ressaltando a perda de liberdade de uma forma mais evidente, apesar de estas ainda se manterem mais presas, em função de seu trabalho dentro e fora de casa. Isto é, quem mais se queixa - o homem - não é de fato quem mais perde! Já no discurso delas, não houve uma resposta preponderante, mas referências de igual monta à perda da individualidade, de privacidade e da liberdade para tomar decisões que envolvem a vida profissional. Apareceu ainda no discurso de homens e mulheres a convicção de que o casamento, na verdade, não apresenta muitas desvantagens. É uma questão de acréscimo, segundo o discurso reproduzido de um deles, ainda que em outras palavras, por quase todos os entrevistados. Perguntados sobre o que fariam de diferente do casamento de seus pais em relação às diferenças à educação dada aos filhos, notamos a importância do diálogo e da maior liberdade, além da busca de criar com os filhos uma relação menos severa e mais amigável. No discurso masculino, surgiu ainda o desejo de ser mais presente do que os pais, o que demonstra, portanto, maior participação masculina por vontade própria na criação e educação dos filhos.

Quanto ao lazer, os hábitos relatados pelos entrevistados são muitíssimo variados, e as diferenças podem, em grande parte, ser creditadas à existência, em graus distintos, de uma estrutura de apoio (babá, avós, empregada) no cuidado com as crianças. Mesmo assim, casais com filhos pequenos 
Segundo a pesquisa realizada por Araújo e Scalon (2005), já citada por nós, em apenas

$7,5 \%$ dos lares há o apoio efetivo de uma empregada doméstica (morando ou não na residência). informaram direcionar sua programação de lazer para atividades que possam ser compartilhadas com as crianças, embora, em alguns casos, tenha havido a menção a atividades exclusivas do casal, nas hipóteses em que o apoio antes referido se faz presente. Assim, o lazer entre os casais pesquisados é fortemente marcado pela presença dos filhos, basicamente em função da faixa etária das crianças, todas em idade escolar, com média de 7 anos. As atividades mais relatadas pelos sujeitos foram (para ambos os sexos): ida ao cinema e a restaurantes, em primeiro lugar, seguidos de shopping, teatro e praia, geralmente incluindo as crianças. Foi no lazer individual que observamos uma forte disparidade entre os sexos. Enquanto os homens relatam que dispõem de um tempo para estar com os amigos, sem a esposa e os filhos (o "futebol" e o "chopinho"), as mulheres relatam ter pouco tempo para o lazer individual. Curioso é que, mesmo com essa diferença, como vimos acima, foram os homens que demandaram mais tempo para o lazer individual, enquanto as mulheres, embora comentando que gostariam de ter esse tempo, não afirmaram ser essa uma necessidade premente. Outros estudos também têm evidenciado que as mulheres (mães) têm menos tempo livre que os homens (pais) (Mattingly \& Bianchi, 2003; Sayer, 2005).

No que tange à divisão de tarefas dentro do lar, todos os entrevistados afirmaram contar com ajuda profissional para a realização das tarefas domésticas (empregada, diarista, folguista) bem como com o auxílio de familiares no que se refere ao cuidado com as crianças. Segundo a pesquisa realizada por Araújo e Scalon (2005), já citada por nós, em apenas $7,5 \%$ dos lares há o apoio efetivo de uma empregada doméstica (morando ou não na residência). Já para o IBGE (2000), 11\% dos lares brasileiros contam, oficialmente, com esse tipo de ajuda. Se confirmados, esses dados sinalizam a nossa amostra como, de fato, um caso à parte da realidade brasileira. Talvez seja no que diz respeito à divisão de tarefas propriamente dita que se dê a mais curiosa conclusão de nossa pesquisa. Por um lado, ambos os sexos parecem estar sendo influenciados por uma visão divulgada pela mídia e pela cultura sobre a igualdade entre os sexos, e declaram ser bastante participativos nas tarefas do lar. Essa participação dos homens se dá, em sua maior parte, nos cuidados com os filhos, muito mais do que nas tarefas da casa. Assim, a responsabilidade com a organização do lar e do trabalho da empregada ainda recai sobre a mulher.

Já as mulheres dizem caber a elas o maior fardo das tarefas e responsabilidades domésticas e com os filhos, e qualificam a participação dos maridos como uma ajuda, na maioria das vezes, bem-vinda e festejada. O que chama a atenção é que, mesmo cientes da disparidade na divisão de tarefas, as mulheres parecem não perceber tal fato como um problema e uma fonte de conflitos, o que demonstra a força da influência de modelos parentais tradicionais no que diz respeito aos papéis de gênero.

Quanto às tarefas domésticas realizadas pelo próprio entrevistado e aquelas realizadas pelo cônjuge, ao cotejarmos as informações prestadas por homens e mulheres, verificamos que os primeiros têm uma função coadjuvante, colaborativa ou periférica, isso segundo os depoimentos das mulheres. Já os homens relataram uma participação maior do que o que foi referido pelas mulheres. É possível que, como os entrevistadores eram todos do sexo feminino, eles possam ter dado respostas mais aceitáveis e agradáveis (efeito pavão). Uma hipótese alternativa (citada adiante) diz respeito a maior distorção perceptiva por parte dos homens, que estariam avaliando sua participação de modo excessivamente favorável. Kamo (2000) lembra também que face às pressões politicamente corretas, muitos homens que pouco fazem em termos 
de trabalhos domésticos compensariam esse gap entre o desejável e o real, superestimando suas contribuições nessa área.

Segundo as respostas obtidas, as mulheres teriam mais responsabilidades com o supermercado, com a administração da casa, dos empregados e da cozinha - o que foi confirmado pelos maridos em suas entrevistas. Já os homens disseram que também vão ao supermercado e, além disso, lavam a louça, fazem pequenos consertos e realizam pagamentos. As mulheres afirmaram que os homens, em sua grande maioria, não fazem nada em casa, em poucos casos, executam algum conserto ou concedem algum tipo de ajuda, e apenas quando solicitados. Embora essa situação pareça injusta, já que muitas vezes a mulher tem igual ou quase igual carga de trabalho fora de casa, no discurso feminino, nem sempre aparece um sinal claro de inconformidade com tal situação. Anos de socialização distinta, em consonância com a perspectiva de gênero, parecem ter inculcado, mesmo em mulheres de alto nível de escolaridade, de classe média e antenadas com os discursos da pós-modernidade, a noção mais tradicional de que tarefas domésticas não precisam mesmo ser divididas igualitariamente entre os sexos.

Só em relação ao cuidado com os filhos a participação masculina foi, de fato, maior, embora persistindo sua característica de subsidiariedade. São as mulheres que ainda dão conta da maioria das tarefas, frequentam reuniões da escola, faltam ao trabalho em caso de doença das crianças, além de qualquer tipo de acompanhamento necessário, seja escolar, médico ou até mesmo no transporte para alguma festinha - sendo que apenas nesse último item os maridos relataram contribuir. A família e as empregadas geralmente auxiliam nesse cuidado, a não ser quando o casal coloca a criança em alguma escola com horário integral. A atuação masculina mostrou-se assim predominantemente complementar à da mulher, salvo naqueles casos, pouco comuns, em que o homem dispunha de horários de trabalho flexíveis e a mulher não. Quanto à apreciação pessoal sobre a divisão de tarefas, revelou-se uma discrepância nos discursos dos entrevistados. Os homens se referiram, como vimos, à sua própria participação nas tarefas como mais intensa e relevante do que aquela percebida pelas mulheres. Elas, por sua vez, se veem fazendo mais do que eles e algumas se ressentem dessa situação manifestando o desejo de dispor de mais tempo para si mesmas. Além da questão do efeito pavão e da necessidade de se mostrarem mais modernos, é possível que os homens estejam simplesmente seguindo o princípio do fenômeno de atribuição de causalidade, quando alocam responsabilidades distintas nas tarefas realizadas, dependendo do fato de serem ora atores, ora observadores (Rodrigues, Assmar, \& Jablonski, 2009). No entanto, quando questionamos o que deveria ser modificado no outro, ou seja, o que o outro não faz, mas deveria fazer, surpreendeu-nos a resposta da maioria, que acreditava não haver necessidade de mudanças. Percebemos que, apesar de uma sobrecarga feminina, não há um conflito de opiniões, reforçando a idéia de que os antigos papéis de gênero ainda são os mais aceitos.

\section{Comentários finais}

Os resultados por nós encontrados são compatíveis com os apurados na maior parte das pesquisas sobre o mesmo tema, tanto no Brasil quanto no exterior. Araújo e Scalon (2005), por exemplo, já citadas por nós, ao apresentar os resultados de pesquisa realizada no Brasil, mas em segmento social diferente (classes populares), referem-se a percepções muito semelhantes com relação à divisão de tarefas: a exemplo do que ocorre na classe média, os homens 
são coadjuvantes nas responsabilidades domésticas. A pesquisa em questão identifica também uma falta de sintonia na percepção de homens e mulheres sobre a divisão de tarefas, com as mulheres percebendo-a como mais assimétrica e os homens mais equitativa, embora ambos demonstrem uma acentuada discrepância entre o que fazem e o que a(o) companheira(o) considera que realmente seja feito. Essas distinções também se apresentam em outras pesquisas, como as levadas a cabo por Kamo (2000) e por Davis e Greenstein (2004). Estes últimos, ao comparar as situações em países tão variados como EUA, Japão, Hungria e Rússia, entre outros, apuraram que os homens tendem a superestimar a sua contribuição nas tarefas domésticas, o que as mulheres não fazem, ao menos não com a mesma intensidade.

Embora tenha havido mudanças significativas no sentido de diminuir o gap entre homens e mulheres no que diz respeito às atividades domésticas (Amato et al., 2007; Robinson \& Godbey, 1997; Sayer, 2005), permanece uma distância considerável entre o discurso e a prática, sendo certo que mesmo os homens cujas atitudes são positivas em relação à divisão de tarefas continuam adotando um comportamento não compatível com tais convicções. O que resulta curioso é a aceitação pelas mulheres de uma situação ainda flagrantemente iníqua, em consonância com o conceito de tradicionalização. Esse conceito é relativo ao fato de homens e mulheres, após se tornarem pais/mães, adotarem posturas mais tradicionais no que tange a seus papéis parentais e a suas divisões de trabalho doméstico, apesar de possíveis atitudes igualitárias anteriores. Essa tendência para a assunção de papéis mais estereotipados se daria independentemente do status profissional das mulheres, do nível educacional ou das atitudes de gênero e das divisões de trabalho preexistentes por parte dos casais. Assim, a divisão de trabalho doméstico costuma ser mais tradicional do que ambos os pais esperavam, daí o epíteto em questão (Brasileiro et al., 2002; Cowan \& Cowan, 2000).

Em suma, o que verificamos é que há ainda um longo percurso a ser feito pelos casais no caminho da igualdade, algo que surpreendentemente não está sendo percebido como tão dificultoso ou conflitivo pelos próprios casais quanto nos parecia antes de levarmos a cabo a presente pesquisa.

\section{Bernardo Jablonski}

Doutor em Psicologia Social - Fundação Getúlio Vargas. Professor assistente da Pontifícia Universidade Católica do Rio de Janeiro, Rio de Janeiro, RJ - Brasil.

Endereço para envio de correspondência:

Rua Marquês de São Vicente, 287/701 Gávea - Rio de Janeiro, RJ - Brasil - CEP 22451-041.

E-mail: bjablonski@uol.com.br

Recebido 15/2/2009, 1a Reformulação 14/8/2009, Aprovado 30/8/2009. 
Anexo I

\section{ROTEIRO DE ENTREVISTAS}

\section{Grupo 1: (informações gerais sobre o entrevistado)}

1. Qual a sua idade? 2. Há quanto tempo você está casado(a)? 3. Você tem filhos? Quantos e de que idades? Eles moram com você? 4. Qual a sua profissão? 5. Quantas horas por dia você normalmente trabalha?

\section{Grupo 2: (opinião sobre o casamento e a educação dos filhos)}

6. Na sua opinião, o que faz durar um casamento? 7. Quais as vantagens e as desvantagens de estar casado(a)? 8. O que você faz diferente de seus pais (no casamento e na educação dos filhos)?

\section{Grupo 3: (lazer)}

9. Vocês costumam sair juntos? Sós ou com os filhos? Com que frequência? 10. O que vocês costumam fazer normalmente?

\section{Grupo 4: (vida doméstica cotidiana)}

11. Como você descreveria o seu dia a dia? 12. Vocês têm ajuda de alguém para as tarefas domésticas? De quem e de que forma? (empregada regular, diarista, folguista, familiares). 13. Quais as tarefas domésticas que cabem a você? E a seu marido/esposa? (abastecer a casa, cozinhar, limpar, cuidar da roupa, efetuar pagamentos, reparos, etc.)

\section{Grupo 5: (cuidado dos filhos)}

14. Com relação aos filhos, que tarefas são realizadas por você e quais por seu marido/esposa? O que fazem em cooperação? (cuidar da higiene e alimentação, auxiliar nas tarefas da escola, acompanhar a médicos/dentistas, comparecer às reuniões da escola, transportar para atividades extracurriculares, outras atividades de lazer, etc.)

15. Nessas atividades, vocês contam com ajuda de alguém? Quem? (babá, empregada, folguista, parente ou agregado) 16 . Se um filho fica doente, quem falta ao trabalho?

\section{Grupo 6: (apreciação pessoal sobre a divisão das tarefas)}

17. O que você acha que seu marido/mulher não faz e deveria fazer? 18. O que você faz e não gostaria de fazer? 19. Há algo que seu marido/mulher faz e que você gostaria de fazer no lugar dele/dela? 

Alone together - How marriage in America is changing. Cambridge: Harvard University Press.

Araújo, C., \& Scalon, C. (2005). Gênero, família e trabalho no Brasil. Rio de Janeiro: FGV.

Artis, J. E., \& Pavalko, E. K. (2003). Explaining the decline in women's household labor: Individual change and cohort differences. Journal of Marriage and the Family, 65, 746-761.

Bardin, L. (1979). Análise de conteúdo. Lisboa: Martins Fontes.

Baxter, J., Hewitt, B., \& Haynes, M. (2008). Life course transitions and housework: Marriage, parenthood, and time on housework. Journal of Marriage and the Family, 70(2), 259272.

Berk, S. F. (1985). The gender factory. New York: Plenum.

Bianchi, S. M., Milkie, M. A., Sayer, L. C., \& Robinson, J. P. (2000). Is anyone doing the housework? Trends in the gender division of household labor. Social Forces, 79, 191-228.

Blair, S. L. (1988). Work roles, domestic roles, and marital quality: Perceptions of fairness among dual-earner couples. Social Justice Research, 11, 313-336.

Blood, R. O., \& Wolfe, D. M. (1960). Husbands and wives: The dynamics of married living. Glencoe, IL: Free.

Brasileiro, R. F., Jablonski, B., \& Féres-Carneiro, T. (2002, julho/dezembro). Papéis de gênero e a transição para a parentalidade. PSICO, 33(2), 289-310.

Brines, J. (1994). Economic dependency, gender, and the division of labor at home American Journal of Sociology, 100 6652-688.

Coltrane, S. (2000). Research on household labor: Modeling and measuring the social embeddedness of routine family work. Journal of Marriage and the Family, 62, 1208-1233.

Coontz, S. (2005). Marriage, a history. New York: Viking.

Cowan, C. P., \& Cowan, P. A. (2000). When partners become parents: The big life change for couples. New Jersey: LEA.

Daly, K. J. (2003, maio). Deconstructing family time: From ideology to lived experience. Journal of Marriage and the Family, 63, 283-294.
Davis, S. N., \& Greenstein, T. N. (2004). Cross-national variation in the division of household labor. Journal of Marriage and the Family, 66(4), 1260-1271.

Demo, D. H. (1992). Parent-child relations: Assessing recent changes. Journal of Marriage and the Family, 54(1), 104-117.

Demo, D. H. (2007, dezembro). What is the divorce rate? A complicated answer to a simple question. Family Focus, F1-F2.

Diniz, G. R. S. (1996). Dilemas de trabalho, papel de gênero e matrimônio em casais que trabalham fora em tempo integral. In T. Féres-Carneiro (Ed.), Relação amorosa, casamento, separação e terapia de casal (pp. 203-228). Rio de Janeiro: ANPEPP.

Dion, K. K., \& Dion, K. L. (1996). Cultural perspectives on romantic love. Personal Relationships, 3, 5-17.

Epstein, R. (2002, fevereiro). My words. Psychology Today, 2, 5.

Famille: les nouveaux pères ont disparu. (2000, 27 de maio). Le Monde.

Família brasileira - pesquisa nacional Datafolha $(2007,07$ de outubro). Folha de S. Paulo (Caderno Especial).

Fehr, B. (2006). A prototype approach to studying love. In R. J. Sternberg \& K. Weis (Eds.), The new psychology of love (pp. 65-83). New Haven: Yale University Press.

Fehr, B., \& Broughton, R. (2001). Gender and personality differences in conceptions of love: An interpersonal theory analysis. Personal Relationships, 8, 115-136.

Féres-Carneiro, T. (1998). Casamento contemporâneo: o difícil convívio entre a individualidade e a conjugalidade. Psicologia: Reflexão e Crítica, 11(2), 379-394.

Féres-Carneiro (2001). Casamento contemporâneo: construção da identidade conjugal. In T. Féres-Carneiro (Ed.), Casamento e família: do social à clínica (pp. 67-80). Rio de Janeiro: Nau.

Ferree, M. M. (1990). Beyond separate spheres: Feminism and family research. Journal of Marriage and the Family, 52(4), 866-884.

Fuwa, M. (2004). Macro-level gender inequality and the division of household labor in 22 countries. American Sociological Review, 69(6), 751-767. 


\section{Referências}

Goldenberg, M. (2000). De Amélias a operárias: um ensaio sobre os conflitos femininos no mercado de trabalho e nas relações conjugais. In M. P. Goldenberg (Ed.), Os novos desejos (pp. 105-124). Rio de Janeiro: Record.

Greenstein, T. N. (1996). Gender ideology and perceptions of the fairness of the division of household labor. Social Forces, 74, 1029-1042.

Hendrick, S. S., \& Hendrick, C. (1995). Gender differences and similarities in sex and love. Personal Relationships, 2, 55-65.

Instituto Brasileiro de Geografia e Estatística. (2000). Recenseamento geral do Brasil. Rio de Janeiro: Autor.

Instituto Brasileiro de Geografia e Estatística. (2005). Estatísticas do Registro Civil. Rio de Janeiro: Autor.

Instituto Brasileiro de Geografia e Estatística. (2007). Gênero e tarefas domésticas. Recuperado em http://ibge.gov.br/home/ presidencia/noticias

Jablonski, B. (1988). A crise do casamento contemporâneo: um estudo psicossocial. Tese de Doutorado, Fundação Getúlio Vargas, Rio de Janeiro.

Jablonski, B. (1996). A aferição de atitudes de jovens solteiros(as) frente à crise do casamento: uma réplica. Cadernos de Psicologia, Série Social e Institucional, 5, 5-21.

Jablonski, B. (1998). Até que a vida nos separe: a crise do casamento contemporâneo (2a ed.). Rio de Janeiro: Agir.

Jablonski, B. (2001). Atitudes frente à crise do casamento. In T. Féres-Carneiro (Ed.), Casamento e família: do social à clínica (pp. 81-95). Rio de Janeiro: NAU.

Jablonski, B. (2003). Afinal, o que quer um casal? Algumas considerações sobre o casamento e a separação na classe média carioca. In T. Féres-Carneiro (Ed.), Família e casal: arranjos e demandas contemporâneas (pp. 141-168). Rio de Janeiro: Loyolla.

Jacobs, J. (2004). Myths that can kill your marriage. Psychology Today, 37(2), 34-38.

Jacobs, J., \& Gerson, K. (1998). Who are the overworked Americans? Review of Social Economy, 4, 442-459.

Kamo, Y. (2000). He said, she said: Assessing discrepancies in husbands' and wives' reports on the division of household labor. Social Science Research, 29, 459-476.

Kluver, E. S., Heesink, J. A. M. \& Van de Vliert, E. (1996). Marita conflict about the division of household labor and paid work Journal of Marriage and the Family, 58, 958-969.

Lavee, Y., \& Katz, R. (2002). Division of labor, perceived fairness, and marital quality: The effect of gender ideology. Journal of Marriage and the Family, 64, 27-39.

Magalhães, A. S. (1993). Individualismo e conjugalidade: um estudo sobre o casamento contemporâneo. Dissertação de Mestrado, Pontifícia Universidade Católica do Rio de Janeiro, Rio de Janeiro.

Mattingly, M. J., \& Bianchi, S. M. (2003). Gender differences in the quantity and quality of free time: The U. S. experience. Social Forces, 81(3), 999-1030.
Moore, S. M., Kennedy, G., Furlonger, B., \& Evers, K. (1999Sex, sex-roles, and romantic attitudes: Finding the balance. Current Research in Social Psychology, 4(3), 10-18.

Peterson, D., \& Shoemaker, M. (1993). Dimensions of romantic attitudes. Perceptual and Motor Skills, 77, 623-633.

Pleck, J. H. (1997). Paternal involvement: Levels, sources and consequences. In M. E. Lamb (Ed.). The role of the father in the child development (pp. 66-103). New York: Wiley.

Robinson, J. P., \& Godbey, G. (1997). Time for life: The surprising ways American use their time. Pennsylvania: The Pennsylvania State University.

Robinson, B. K., \& Hunter, E. (2008). Is mom still doing it all? Reexamining depictions of family work in popular advertising. Journal of Family Issues, 29(4), 465-486.

Rocha-Coutinho, M. L. (2003). Quando o executivo é uma dama: a mulher, a carreira e as relações familiares. In T. Féres-Carneiro (Ed.), Família e casal: arranjos e demandas contemporâneas. Rio de Janeiro: Ed. da PUC-Rio.

Rocha-Coutinho, M. L. (2004). Variações sobre um antigo tema: a maternidade e a paternidade para mulheres com uma carreira profissional bem sucedida. Trabalho apresentado na 10 Reunião da ANPEPP, Praia Formosa, Espírito Santo.

Rocha-Coutinho, M. L. (2005). O papel de homens e mulheres na família: podemos falar em reestruturação? Psicologia Clínica, 15(2), 93-108.

Rocha-Coutinho, M. L. (2007). Família e emprego: conflitos e expectativas de mulheres executivas e de mulheres com um trabalho. In T. Féres-Carneiro (Ed.), Família e casal: saúde, trabalho e modos de vinculação (pp. 203-228). São Paulo: Casa do Psicólogo.

Rodrigues, A., Assmar, E., \& Jablonski, B. (2009). Psicologia social (27a ed., rev. e ampl.). Petrópolis, RJ: Vozes.

Sayer, L. C. (2005). Gender, time and inequality; Trends in women's and men's paid work, unpaid work and free time. Social Forces, 84(1), 285-303.

Sayer, L. C., Bianchi, S. M., \& Robinson, J. P. (2004). Are parents investing less in children? Trends in mothers' and fathers' time with children. American Journal of Sociology, 110, 1-43.

Sayer, L. C. Philip, N. C \& Casper, L. M (2004). Women, men and work. The American People Census 2000, New York - N.Y. Russel Sage Foundation and Population Reference Bureau.

Schoen, R. \& Canudas-Romo, V. (2006). Timing effects on divorce: 20th century experience in the USA. Journal of Marriage and the Family, 68, 749-758.

Singelis, T., Choo, P., \& Hatfield, E. (1995). Love schemas and romantic love. Journal of Social Behavior and Personality, 10, 15-36.

Skolnick, A. (2006, dezembro). The family and its future. Family Focus, F3-F4.

Thistle, S. (2006). From marriage to the market: The transformation of women's lives and work. Los Angeles, CA: University of California Press.

Thompson, L. (1995). The place of feminism in family studies. Journal of Marriage and the Family, 57, 847-865.

Vaitsman, J. (1994). Flexíveis e plurais: identidade, casamento e família em circunstâncias pós-modernas. Rio de Janeiro: Rocco. 